\title{
Responses of mice to murine coronavirus immunization
}

\author{
A. L. Smith ${ }^{1,2}$, M. S. de Souza ${ }^{1,2}$, D. Finzi ${ }^{2}$, and S. W. Barthold ${ }^{1}$ \\ ${ }^{1}$ Section of Comparative Medicine and ${ }^{2}$ Department of Epidemiology and Public Health, \\ Yale University School of Medicine, New Haven, Connecticut, U.S.A.
}

Accepted December 19, 1991

Summary. Oral and/or intranasal inoculation of susceptible mouse genotypes with the JHM strain of mouse hepatitis virus (MHV-JHM) consistently results in $T$ cell dysfunction as reflected by in vitro proliferative responses to mitogens or allogeneic cells. One approach to examining the mechanism responsible for the observed functional $\mathrm{T}$ cell suppression is to determine whether virus replication is required for its induction. To this end, mice were inoculated oronasally with MHV-JHM that was inactivated with short-wave ultraviolet light, betapropiolactone or psoralen. Mice were also inoculated with live MHV-JHM after recovery from homotypic or heterotypic MHV infection. Spleen cells from BALB mice inoculated oronasally with inactivated MHV-JHM yielded extremely variable in vitro proliferative responses after concanavalin A stimulation. MHV-susceptible mice exposed oronasally or intraperitoneally to virus inactivated by any of the minimum effective treatments failed to seroconvert. Immunization with psoralen-treated virus intraperitoneally in Freund's complete adjuvant or oronasally failed to protect from live virus challenge, but survivors had elevated virus-specific serum IgG antibody titers compared to mock-immunized controls at two weeks post-challenge. Spleen cells from mice that were challenged after recovery from homotypic live virus infection did not exhibit the profound in vitro $T$ cell suppression normally observed during the acute stage of primary infection. In contrast, MHV-JHM challenge of mice vaccinated with heterotypic live MHV-S resulted in significantly depressed in vitro $T$ cell function. The combined data suggest that either virus replication or exposure to more concentrated antigen may be required for induction of the dramatic $\mathrm{T}$ cell dysfunction that occurs as a consequence of MHV-JHM infection as well as for a detectable MHV-specific humoral response.

\section{Introduction}

Mouse hepatitis virus (MHV) is a highly contagious coronavirus infecting laboratory mice worldwide at high prevalence $[21,22,25,38]$, usually without 
A. L. Smith et al.

clinical signs. The impact of infection on research involving mice is enormous, with several adverse effects on biological responses of mice having been demonstrated $[3-5,9,12-14,33,34,36]$. Infection has the potential to render experimental results in a number of disciplines invalid. A major adverse effect of MHV infection is immunomodulation [9, 13, 14, 33, 36].

Prior studies have shown that susceptible strains of mice, such as the BALB/ c, sustain transiently suppressed $T$ cell function as a consequence of infection by a natural route with the JHM strain of $\operatorname{MHV}[13,14,33,36]$. An important issue pertaining to the mechanism responsible for this immunosuppression is whether virus replication is required for its induction. Studies with other viruses have yielded varying results. Measles virus-associated inhibition of mitogendriven proliferation and immunoglobulin production is eliminated when UVor heat-inactivated virus is used $[24,26]$. The immunosuppressive variant of the parvovirus, minute virus of mice, did not inhibit the appearance of cytotoxic $\mathrm{T}$ cells in mixed lymphocyte cultures if used in the form of $\mathrm{UV}$-inactivated virus or purified viral capsids [15]. Live Newcastle disease virus, which does not achieve a full replication cycle in murine cells, induced suppressed concanavalin A (Con A)-driven and allogeneic responses in mice, whereas UV-inactivated virus did not [11]. In contrast, inhibition of the poxvirus DNA polymerase with phosphonoacetic acid did not affect the ability of malignant rabbit fibroma virus to suppress lymphocyte proliferation or initiation of antibody production [37]. Proliferation of bovine peripheral blood mononuclear cells stimulated by either Con A or interleukin (IL) 2 was inhibited by bovine herpesvirus 1, although less than $0.1 \%$ of the cells were productively infected [8]. In a model system using human peripheral blood lymphocytes and vesicular stomatitis virus, Sendai virus, Friend leukemia virus, herpes virus types 1 and 2, or a battery of avian retroviruses known to be incapable of entering and infecting human lymphocytes, both live and UV-inactivated viruses abrogated proliferative responses both to mitogens (Con $\mathrm{A}$ and phytohemagglutinin) and allogeneic cells $[27,39,40]$. Thus, the ability of replication-defective virus to alter immune function is unpredictable.

The major goal of this study was to determine whether the $T$ cell dysfunction observed after MHV inoculation of a susceptible genotype by a natural route is due directly to active virus infection or indirectly to interaction with MHV antigens. The goal was addressed by characterizing the responses of mice that were exposed to virus inactivated by any of several physical or chemical methods and of mice that were challenged after recovery from live virus immunization.

\section{Materials and methods}

Virus

MHV-JHM and MHV-S (American Type Culture Collection, Rockville, MD) were used in the form of infected infant mouse brain homogenates. Both virus stocks had titers of $10^{7.3}$ intracerebral infant mouse $\mathrm{LD}_{50}$ per $\mathrm{ml}$. Mice inoculated oronasally received $10^{5.6}$ 
icLD $D_{50}$-equivalents, and mice inoculated intraperitoneally received $10^{6.3} \mathrm{icLD}_{50}$-equivalents of virus.

\section{Mice}

Female BALB/cByJ (BALB) mice (The Jackson Laboratory, Bar Harbor, ME) were four weeks old at the time of initial virus exposure. Cr: ORL Sencar (hereafter referred to as Sencar) dams with litters and weanling female Sencar and NIH Swiss mice were obtained from the Animal Genetics and Production Branch, NCI (Frederick, MD). Randomly selected mice were free of antibody to common murine viruses on arrival. All mice were housed in micro-isolator cages (Lab Products, Maywood, NJ) and were given food and water ad libitum. Manipulations and husbandry were performed in a class II biological safety cabinet. An open-cage sentinel mouse seromonitoring program was in place during the course of the reported studies. Seroconversion to none of 11 common murine viruses or Mycoplasma pulmonis was detected, except among selected MHV-inoculated mice as detailed in the Results.

\section{Chemicals, reagents and antibodies}

Beta-propiolactone (3-hydroxypropionic acid lactone; Sigma Chemical Co., St. Louis, MO) was used as a $1 \%$ stock solution. Psoralen (4'-aminomethyl-4,5'8-trimethylpsoralen hydrochloride; HRI Associates, Inc., Emeryville, CA) was prepared as a $1 \mathrm{mg} / \mathrm{ml}$ stock solution in $50 \%$ ethyl alcohol, stored at room temperature in a light-tight container and used at a final concentration of $10 \mu \mathrm{g} / \mathrm{ml}$. Concanavalin A (Con A; Sigma Chemical Co.) was used at a final concentration of $2 \mu \mathrm{g} / \mathrm{ml}$. Rat monoclonal antibodies to mouse IL2, designated S4B6 [28], and IL4, designated 11B11 [29], were originally obtained from T. Mosmann (S4B6) and J. Ohara and W. E. Paul (11B11) and were kindly provided by Dr. Kim Bottomly (Section of Immunobiology and Howard Hughes Medical Institute, Yale University).

\section{Virus inactivation procedures}

Short-wave ultraviolet (UV) irradiation results in the formation of pyrimidine dimers [17] and was accomplished by exposing a thin layer of stock virus in a glass petri dish within an ice bath to a GTE $30 \mathrm{~W}$ germicidal lamp at a distance of six inches for $10 \mathrm{~min}$.

Beta-propiolactone (BPL) is an alkylating agent that reacts with guanidine residues of RNA and DNA and is considered moderately effective in maintaining antigenic structure [23]. BPL inactivation was accomplished by adding one volume of the $1 \%$ stock solution to nine volumes of stock virus. The mixture was incubated for $1 \mathrm{~h}$ in a $37^{\circ} \mathrm{C}$ water bath, aliquoted and stored at $-70^{\circ} \mathrm{C}$.

Psoralens are naturally occurring aromatic compounds found in many fruits and vegetables and are chemically inert until exposed to long-wave UV light resulting in direct photoreaction with nucleic acids [17]. The linear psoralen molecule intercalates in a double helical region and forms covalent adducts with pyrimidine bases, usually thymidine in DNA and uridine in RNA [10]. The bonds formed firmly link together and prevent the separation of double helical nucleic acid strands without disruption of protein structure [17]. For psoralen inactivation, $4^{\prime}$-aminomethyl-4,5',8-trimethylpsoralen hydrochloride was added at a final concentration of $10 \mu \mathrm{g} / \mathrm{ml}$ to a shallow layer of stock virus in a petri dish that was manually swirled during the irradiation periods and transferred to an ice bath during sampling periods. Ultraviolet irradiation from below was accomplished with a long-wave UV transilluminator (model TL33, UVP, Inc., San Gabriel, CA) emitting at a wavelength of $365 \mathrm{~nm}$ with an average intensity of $7000 \mu \mathrm{W} / \mathrm{cm}^{2}$. Aliquots were removed after 0 (prior to UV light exposure), 1, 2, 3, 4, 5, 7 and $10 \mathrm{~min}$ and stored at $-70^{\circ} \mathrm{C}$. 
A. L. Smith et al.

\section{Confirmation of virus inactivation}

Each virus preparation treated as described above was assayed by intracerebral inoculation of two-day-old Sencar mice that were observed daily for mortality. This infant mouse bioassay currently serves as the most sensitive test for MHV infectivity [13]. In addition, livers from BALB mice inoculated oronasally with either UV-inactivated or BPL-treated MHV and used for functional T cell assays were processed for histology. They were fixed in $10 \%$ neutral buffered formalin, embedded in paraffin, sectioned at $5 \mu \mathrm{m}$ and stained with hematoxylin and eosin. The concentration of infectious virus in the liver is very high during the acute phase of active infection $[1,32]$, and there is a $100 \%$ correlation between liver histopathology and virus recovery from this major target organ (Smith and Barthold, unpubl. obs.). Inactivation of psoralen-treated MHV-JHM was further confirmed by the inability of primers specific for a segment of the $M$ gene to amplify in polymerase chain reaction [19].

\section{Serology}

Antigenicity of virus that was confirmed to be inactivated was tested by intraperitoneal and/or oronasal inoculation of weanling Sencar or BALB mice that were exsanguinated 21 or 28 days later. Sera were screened for MHV antibody by indirect immunofluorescence (IFA) using sera diluted 1:10 and bivalent MHV-JHM/MHV-S antigen and by an IgG enzyme immunoassay (EIA) using sera diluted 1:50 and MHV-JHM antigen as previously described [31, 35]. Antibody titers were determined by EIA.

\section{Spleen cell proliferative assays}

Con A-stimulated proliferation was measured as previously described [14, 33, 36]. Briefly, spleen cells from individual BALB mice exposed oronasally to inactivated or live virus four, five or seven days earlier were suspended in $5 \mathrm{ml}$ of RPMI 1640 medium (Gibco BRL, Gaithersburg, MD) containing 5\% fetal bovine serum (Gibco BRL), $0.05 \mathrm{mM}$ 2-mercaptoethanol (Sigma Chemical Co.) and $2 \mathrm{mM}$ L-glutamine (Gibco BRL) [RPMI 95-5]. Cell suspensions were diluted as needed in filtered normal saline containing $0.2 \%$ trypan blue and $1.7 \%$ ammonium chloride to determine viable nucleated cell counts. The cells were then washed, adjusted to $2 \times 10^{6}$ viable cells per $\mathrm{ml}$ in RPMI $95-5$, and $100 \mu \mathrm{l}$ of cell suspension were added to well of 96-well cluster dishes. Each set of four or six replicate wells received $100 \mu$ l of RPMI 95-5 or $100 \mu \mathrm{l}$ of Con $\mathrm{A}$. The cells were incubated in a $37^{\circ} \mathrm{C}$, $5 \% \quad \mathrm{CO}_{2}$ humidified atmosphere and were labeled with $1 \mu \mathrm{Ci}$ per well of methyl $\left[{ }^{3} \mathrm{H}\right]$ thymidine (Dupont NEN, Boston, MA; $80 \mathrm{Ci}$ per mmol) $24 \mathrm{~h}$ prior to collection on glass fiber filters for scintillation counting. Cultures were harvested either after $72 \mathrm{~h}$ or at $24 \mathrm{~h}$ intervals from days 2 through 6 [14]. Results are expressed as [mean cpm for Con A-treated cells - mean cpm for RPMI 95-5-treated cells].

\section{IL2 bioassays}

Supernates collected from spleen cells cultured with Con A or RPMI $95-5$ for $24 \mathrm{~h}$ were assyed on CTLL-2 cells $[16,41]$ as described earlier $[14,33,36]$. Supernates from Con Astimulated cultures that induced proliferation of CTLL-2 cells were serially diluted and retested with S4B6 (anti-IL2) and 11B11 (anti-IL4) monoclonal antibodies [14, 36].

\section{Vaccination-challenge experiments}

Virus that was exposed to psoralen and long-wave UV light for 3 min was used to vaccinate weanling mice. BALB mice were twice vaccinated oronasally at two week intervals. NIH Swiss mice were inoculated intraperitoneally with killed virus emulsified in Freund's com- 
plete adjuvant and boosted oronasally two weeks later. Control mice were similarly inoculated with sterile culture medium or uninfected infant mouse brain homogenate emulsified in Freund's complete adjuvant. Two weeks after the booster dose, a drop of blood was collected from the tip of the tail for serology, and the mice were challenged intranasally with $10^{5.3} \mathrm{icLD}_{50}$ of live MHV-JHM. The mice were observed for mortality and exsanguinated at 14 days post-challenge.

To determine the effect of prior vaccination with live virus on in vitro $T$ cell function after subsequent challenge, BALB mice were inoculated oronasally with sterile culture medium, MHV-JHM or MHV-S. After four weeks, an interval in which mice fully recover from oronasal MHV infection, small blood samples were collected to verify seroconversion, and all of the mice were challenged oronasally with MHV-JHM. Con A-induced proliferation and IL 2 production by spleen cells collected four days after challenge were measured as described above.

\section{Results}

\section{$U V$-inactivated $M H V$}

Based on the infant mouse bioassay, MHV-JHM was completely inactivated by exposure to a germicidal UV lamp for ten minutes. Weanling BALB mice exposed oronasally to this material and used for functional $\mathrm{T}$ cell assays had histologically normal livers at four and seven days post-inoculation, further confirming inactivation of the inoculum. These mice also failed to seroconvert. Mice similarly exposed to live virus seroconverted by seven days post-inoculation and had moderate hepatitis on day 4 that increased in severity by day 7. Con A-stimulated proliferative responses of spleen cells from five of six mice assayed at four days after exposure to UV-inactivated MHV were significantly reduced compared to control responses (Table 1). Spleen cells from one mouse were hyper-responsive. At day 7, cells from four of six mice that received UVinactivated MHV proliferated poorly compared to controls and cells from two mice were hyper-responsive. Cells from actively infected mice were still functionally suppressed at this interval, with proliferative values of 9 to $15 \%$ of control (Table 1). IL2 production by cultured spleen cells was generally correlated with proliferative capacity (Table 1). The data shown for UV-inactivated virus represent one of three replicate experiments, all of which yielded similarly highly variable responses for cells from mice given killed MHV-JHM.

\section{Beta-propiolactone-inactivated $M H V$}

BALB mice given BPL-inactivated MHV-JHM oronasally 7 or 14 days prior to necropsy had histologically normal livers, confirming virus inactivation. These mice failed to seroconvert by day 21 . Mice similarly exposed to live virus had severe hepatitis on day seven and were seropositive on day 14. Con Astimulated proliferative responses of spleen cells from mice given BPL-inactivated MHV seven days earlier were consistently elevated compared to control responses, whereas responses of cells from actively infected mice ranged from 16 to $47 \%$ of control proliferation (Table 1). Mouse-to-mouse variability in 
A. L. Smith et al.

Table 1. In vitro $T$ cell function of spleen cells from individual BALB/cByJ mice inoculated oronasally with live or inactivated MHV-JHM prior to assay

\begin{tabular}{|c|c|c|c|c|}
\hline \multirow{3}{*}{$\begin{array}{l}\text { Day post- } \\
\text { inoculation }\end{array}$} & \multirow[t]{3}{*}{ Inoculum } & \multicolumn{3}{|c|}{ Inactivation method } \\
\hline & & \multicolumn{2}{|c|}{ Ultraviolet light } & \multirow{2}{*}{$\frac{\text { Beta-propiolactone }}{\text { Con A CPM }}$} \\
\hline & & Con A CPM & IL2 $\mathrm{CPM}^{\mathrm{a}, \mathrm{b}}$ & \\
\hline \multirow[t]{2}{*}{4} & $\begin{array}{l}\text { Controls (4) } \\
\text { Live virus }\end{array}$ & $\begin{array}{l}20.9 \pm 11.6 \\
1.1(5) \\
1.0(5) \\
8.2(39) \\
0.0(0) \\
1.6(7)\end{array}$ & $\begin{array}{c}45.6 \pm 9.4 \\
8.4(18) \\
1.3(3) \\
37.9(83) \\
1.4(3) \\
2.5(5)\end{array}$ & \\
\hline & Inactivated virus & $\begin{array}{c}2.6(12) \\
0.9(4) \\
3.3(16) \\
7.7(37) \\
3.0(14) \\
43.3(207)\end{array}$ & $\begin{array}{l}\text { N.D. } \\
1.2(3) \\
7.9(17) \\
32.9(72) \\
34.2(75) \\
43.1(94)\end{array}$ & \\
\hline \multirow[t]{2}{*}{7} & $\begin{array}{l}\text { Controls (4) } \\
\text { Live virus }\end{array}$ & $\begin{array}{l}65.2 \pm 38.5 \\
6.1(9) \\
9.6(15) \\
4.5(7) \\
8.3(13) \\
8.4(13)\end{array}$ & $\begin{array}{l}99.8 \pm 15.1 \\
3.7(4) \\
6.8(7) \\
0.4(0) \\
20.5(21) \\
9.7(10)\end{array}$ & $\begin{array}{l}99.9 \pm 18.4 \\
29.1(29) \\
46.7(47) \\
25.0(25) \\
15.8(16) \\
18.8(19)\end{array}$ \\
\hline & Inactivated virus & $\begin{array}{c}58.1(89) \\
187.2(287) \\
53.0(81) \\
41.1(63) \\
127.6(196) \\
30.2(46)\end{array}$ & $\begin{array}{c}42.6(43) \\
111.7(112) \\
58.1(58) \\
25.8(26) \\
113.1(113) \\
84.5(85)\end{array}$ & $\begin{array}{l}168.2(168) \\
153.6(154) \\
143.5(144) \\
151.3(151)\end{array}$ \\
\hline
\end{tabular}

${ }^{a}$ Counts per minute $\times 10^{-3}$ (\% of mean control CPM). Control CPM are expressed as mean \pm S.D. for four individual mice

${ }^{\mathrm{b}}$ IL 2 results are for $24 \mathrm{~h}$ culture supernates diluted $1: 2$

${ }^{\mathrm{c}}$ Not done

spleen cell proliferation was minimal in four replicate experiments using BPLtreated MHV-JHM as the inoculum.

\section{Psoralen-inactivated $M H V$}

All Sencar pups ( 8 per group) exposed intracerebrally to virus treated with psoralen for two minutes or longer survived (Fig. 1). Virus collected at each interval exceeding two minutes was inoculated intraperitoneally into groups of four weanling Sencar mice. All survived for three weeks, and none developed MHV antibody. Five BALB mice were exposed oronasally to virus treated for 


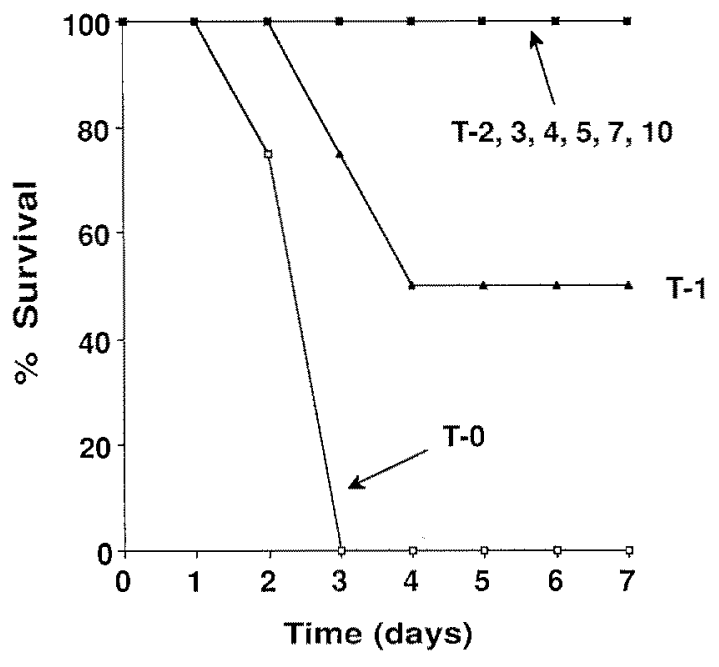

Fig. 1. Survival curves for infant Sencar mice inoculated intracerebrally with MHV-JHM exposed to psoralen alone $(T-0)$ or to psoralen plus longwave UV light for $1(T-1)$ or $2,3,4,5$, 7 or $10 \mathrm{~min}$

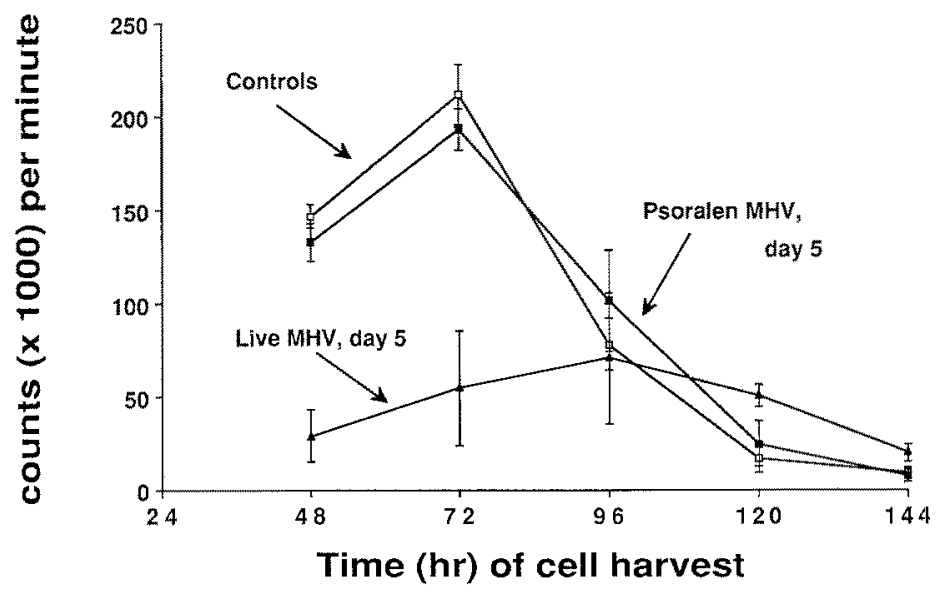

Fig. 2. Concanavalin A-induced proliferative responses of spleen cells from BALB/cByJ mice inoculated oronasally five days prior to assay with live MHV-JHM or MHV-JHM treated for $3 \mathrm{~min}$ with psoralen and long-wave UV light. Cells were harvested for scintillation counting at $24 \mathrm{~h}$ intervals from 48 to $144 \mathrm{~h}$ post-initiation of cultures

three minutes with psoralen and long-wave UV light, and spleen cell proliferative responses were measured five days later (Fig. 2). Proliferation of cells cultured for two to six days was essentially identical to that of cells from three naive control mice. In contrast, proliferation of spleen cells derived from four actively infected mice was significantly reduced with peak proliferation occurring later than that of control cells, as reported earlier [14].

The immunogenicity of psoralen-inactivated MHV-JHM was tested in three vaccination-challenge experiments (Table 2). Data pooled from two experiments in which BALB mice were twice exposed oronasally to psoralen-treated virus yielded identical mortality rates and average survival times ( 7.9 days) for vaccinated and control mice. Both experiments yielded modestly elevated post- 
Table 2. Mortality and serum antibody responses of mice twice vaccinated with psoraleninactivated MHV-JHM and challenged intranasally with live virus

\begin{tabular}{llcc}
\hline Vaccine type & Vaccine route & \multicolumn{2}{c}{ No. dead/No. challenged (\%) GMT $^{\mathrm{a}}$} \\
\hline Mock & O.N. & $9 / 24(38)$ & $463 \pm 134$ \\
Psoralen-MHV & O.N. & $14 / 37(38)$ & $706 \pm 154$ \\
Mock & I.P. (+FCA)/O.N. & $1 / 10(10)$ & $516 \pm 69$ \\
Psoralen-MHV & I.P. (+FCA)/O.N. & $3 / 10(30)$ & $5,760 \pm 210$ \\
\hline
\end{tabular}

${ }^{a}$ Geometric mean IgG antibody titer \pm S.D. determined by MHV-JHM enzyme immunoassay two weeks after live virus challenge

${ }^{b} \mathrm{BALB} / \mathrm{cByJ}$ mice were inoculated oronasally with sterile culture medium or psoralentreated MHV-JHM twice at 14 day intervals

${ }^{\mathrm{c}} \mathrm{NIH}$ Swiss mice were inoculated intraperitoneally with uninfected infant mouse brain homogenate or psoralen-treated MHV-JHM emulsified in Freund's complete adjuvant (FCA). Fourteen days later they were inoculated oronasally with the same preparations in the absence of adjuvant

challenge MHV-specific antibody titers in vaccinated mice (Table 2). NIH Swiss mice exposed intraperitoneally to psoralen-treated virus emulsified in Freund's complete adjuvant and boosted oronasally also were not protected from challenge, but had significantly elevated post-challenge virus-specific IgG antibody titers (Table 2). None of 50 mice tested on the day of live virus challenge were MHV seropositive.

\section{$T$ cell function of mice challenged after live virus vaccination}

Spleen cells from four mock-vaccinated BALB mice that were challenged with MHV-JHM proliferated at levels that were 1 to $5 \%$ of control spleen cell proliferation (Table 3). These cells also produced negligible concentrations of IL2. In contrast, cells from four mice immunized with homologous (MHVJHM) virus yielded proliferative responses that were 39 to $67 \%$ of control responses (Table 3). Spleen cells from six of 12 mice vaccinated with heterologous (MHV-S) virus proliferated at a level that was less than $10 \%$ of control proliferation (Table 3). Proliferation of cells from the remaining six mice ranged from 11 to $42 \%$ of control proliferation. IL 2 production was generally correlated with the magnitude of the proliferative response (Table 3 ), and serial dilutions yielded the expected dose-response curve (data not shown).

IFA testing of sera from MHV-JHM- and MHV-S-immunized mice revealed that all of the mice were MHV antibody-positive at the time of MHV-JHM challenge, whereas sera from controls or mice that were mock-vaccinated did not contain detectable antibody. At four days after MHV-JHM challenge, sera from control mice and mock-vaccinated mice did not contain MHV-JHMreactive EIA antibody (Table 3). Mice vaccinated with MHV-JHM had high titered serum IgG antibody (geometric mean EIA titer $=1: 22,400$ ). Sera from 
Table 3. Concanavalin A-induced proliferation and IL2 production by spleen cells from individual BALB/cByJ mice that were mock-vaccinated or vaccinated with live MHV-JHM (JHM) or live MHV-S (S) four weeks prior to MHV-JHM challenge

\begin{tabular}{|c|c|c|c|c|c|c|}
\hline Group & $\begin{array}{l}\text { Day post- } \\
\text { challenge }\end{array}$ & $\begin{array}{l}\text { Con A } \\
\text { CPM }^{\mathrm{a}}\end{array}$ & $\begin{array}{l}\text { Percent of } \\
\text { mean Con } \\
\text { A control }\end{array}$ & $\begin{array}{l}\text { IL2 } \\
\text { CPM }^{\mathrm{a}, \mathrm{b}}\end{array}$ & $\begin{array}{l}\text { Percent } \\
\text { of mean } \\
\text { IL } 2 \text { control }\end{array}$ & $\begin{array}{l}\text { MHV-JHM } \\
\text { antibody } \\
\text { titer }\end{array}$ \\
\hline Controls (4) & & $134.5 \pm 16.5$ & & $101.2 \pm 5.3$ & & $<50$ \\
\hline Mock/JHM & 4 & $\begin{array}{l}1.8 \\
3.1 \\
6.2 \\
2.3\end{array}$ & $\begin{array}{l}1 \\
2 \\
5 \\
2\end{array}$ & $\begin{array}{l}3.6 \\
5.3 \\
3.2 \\
0.2\end{array}$ & $\begin{array}{l}4 \\
5 \\
3 \\
0\end{array}$ & $\begin{array}{l}<50 \\
<50 \\
<50 \\
<50\end{array}$ \\
\hline JHM/JHM & 4 & $\begin{array}{l}77.4 \\
68.3 \\
89.7 \\
52.3\end{array}$ & $\begin{array}{l}58 \\
51 \\
67 \\
39\end{array}$ & $\begin{array}{r}62.9 \\
11.9 \\
43.6 \\
100.0\end{array}$ & $\begin{array}{l}62 \\
12 \\
43 \\
99\end{array}$ & $\begin{array}{l}25,600 \\
25,600 \\
25,600 \\
12,800\end{array}$ \\
\hline S/JHM & 4 & $\begin{array}{r}22.9 \\
39.5 \\
6.4 \\
10.6 \\
14.9 \\
22.0 \\
7.6 \\
9.1 \\
12.1 \\
11.8 \\
27.8 \\
57.0\end{array}$ & $\begin{array}{r}17 \\
29 \\
5 \\
8 \\
11 \\
16 \\
6 \\
7 \\
9 \\
9 \\
21 \\
42\end{array}$ & $\begin{array}{r}29.6 \\
63.5 \\
1.3 \\
16.7 \\
10.3 \\
33.1 \\
15.2 \\
1.6 \\
5.2 \\
13.3 \\
17.1 \\
30.1\end{array}$ & $\begin{array}{r}29 \\
63 \\
1 \\
16 \\
10 \\
33 \\
15 \\
2 \\
5 \\
13 \\
17 \\
30\end{array}$ & $\begin{array}{r}100 \\
100 \\
800 \\
200 \\
<100 \\
100 \\
100 \\
<100 \\
<100 \\
100 \\
<100 \\
100\end{array}$ \\
\hline
\end{tabular}

${ }^{a}$ Results are given as counts per minute $\times 10^{-3}$. Control CPM are expressed as mean \pm S.D. for four individual mice

${ }^{\mathrm{b}}$ IL2 results are for $24 \mathrm{~h}$ culture supernates diluted $1: 2$

eight of 12 MHV-S-vaccinated mice contained MHV-JHM-reactive EIA antibody, and the geometric mean IgG titer for those positive sera was more than 100 times lower than that for MHV-JHM-vaccinated mice.

\section{Discussion}

The goal of the reported experiments was to determine whether MHV-JHM replication is required for induction of the profound $\mathrm{T}$ cell dysfunction observed after inoculation of susceptible mice by natural routes. The results suggest that functional $\mathrm{T}$ cell suppression as a consequence of oronasal exposure to inactivated MHV-JHM depends heavily on the method used to kill the virus. Spleen cells from five of six mice given UV-inactivated virus four days prior to assay proliferated poorly to Con A stimulation. A trend toward more normal function 
was seen by seven days after inoculation, with cells from two of six mice being hyper-responsive at that interval. Cells from four of four mice given BPLinactivated virus and tested seven days later were hyper-responsive. Responses of cells from mice given UV-treated MHV-JHM were quite variable in three separate experiments, despite the fact that confirmation of virus inactivation was obtained for each inoculated mouse.

Spleen cells from mice given psoralen-treated virus yielded Con A-induced proliferative responses that were essentially identical to those of cells from naive control mice. Mouse-to-mouse variation was minimal among animals that received psoralen-treated MHV-JHM. Of the inactivation methods used, psoralen treatment is the least harsh and therefore least likely to cause conformational changes in structural proteins [17]. The lack of a detectable virus-specific humoral response even after two exposures to psoralen-treated virus, including one parenteral injection in Freund's complete adjuvant, renders interpretation and conclusions difficult. It could be argued, however, that the immune systems of mice twice immunized with psoralen-inactivated virus were stimulated, since these mice had consistently, albeit marginally in the case of oronasal inoculation, elevated antibody titers compared to mock-vaccinated mice after live virus challenge.

Mice given MHV-JHM inactivated by any of the methods described clearly did not receive enough antigen to induce seroconversion. It may also be argued that oronasal exposure to killed virus may be less likely to stimulate an immune response than parenteral inoculation, with or without adjuvant. However, our research program has historically been devoted to studies of MHV as a natural pathogen of laboratory mice. We have, therefore, always used natural routes of exposure. The studies in which immunosuppression by live MHV-JHM were documented $[13,14,33,36]$ were performed with mice infected orally, intranasally or by the combined routes. It therefore seemed reasonable, if not essential, to expose mice to killed virus by the same natural routes in attempts to determine whether such virus could induce immune dysfunction.

The accumulated data from studies using three inactivation methods also provide support for the notion that virus replication or exposure to more antigen is required for induction of a detectable antibody response to and protection from challenge with MHV-JHM. This contrasts with reports for other viruses. For instance, arthropod-borne viruses and ecologically related viruses that cause high mortality among peripherally inoculated mice are frequently BPL-inactivated in order to prepare immune sera [7]. Reports on the immunogenicity of psoralen-treated virus are rare; however, psoralen-inactivated crude Pichinde virus, without adjuvant, induced seroconversion among intramuscularly injected guinea pigs within two weeks [17]. Guinea pigs given two doses of virus that was 25 -fold more dilute, again without adjuvant, also seroconverted [17]. In addition to the methods reported here, we also evaluated the ability of formalininactivated MHV-JHM to induce an antibody response, using a modification of a recently published technique [18]. In that study, inoculation of mice with 
lactic dehydrogenase elevating virus treated with $0.06 \%$ formalin at $37^{\circ} \mathrm{C}$ for as long as $5 \mathrm{~h}$ yielded hybridomas that produced virus neutralizing antibody [18]. Treatment of MHV-JHM with $0.05 \%$ formalin at $37^{\circ} \mathrm{C}$ for $25 \mathrm{~min}$ (minimum effective treatment time) resulted in complete loss of infectivity. However, Sencar mice inoculated oronasally or intraperitoneally with that material had not seroconverted when tested 21 days later. Formalin seemed a reasonable treatment choice, since higher concentrations do not destroy MHV antigens $[6,35]$. The possibility that an antibody response could be stimulated by parenteral inoculation of mice with inactivated MHV-JHM in a potent adjuvant, perhaps with several boosters, cannot be excluded. However, as stated above, the major goal of the reported studies was to characterize $T$ cell function of mice given killed virus by a natural route.

In view of the high prevalence of MHV infection and the rapidity with which the virus is transmitted throughout a colony, control by means of elimination of the agent, as has been the case with ectromelia (mousepox) virus [30], seems an unlikely possibility. One strategy is development of a vaccine that might provide protection without the functional immune deficits documented after live virus administration. Since protection from challenge was not afforded by psoralen-inactivated virus, immune function of mice challenged after live virus vaccination was evaluated. The design of the live virus vaccination-challenge experiments reported here was identical to that described in an earlier report [2], in which complete resistance to homotypic challenge was demonstrated. In the earlier study, BALB mice that were challenged 30 days after an immunizing infection with MHV-JHM had histologically normal livers and noses four days after challenge, and virus was not detected in livers at that interval. This was strong evidence that homotypic live virus vaccination protected against infection upon challenge. In contrast, mice immunized with biologically similar, but antigenically distinct, MHV-S were fully susceptible to MHV-JHM challenge, based on the same criteria [2]. In the present study, spleen cells from mice challenged with MHV-JHM after recovery from homotypic infection yielded Con $\mathrm{A}$-induced proliferative responses that were suppressed, but not to the extent observed for cells from mice undergoing primary infection (Mock/ JHM in Table 3). Function of cells from mice immunized with live MHV-S and challenged with MHV-JHM was suppressed in a manner similar to that of cells from mice sustaining primary infection. These data affirm by different methodology the earlier report of highly strain-specific challenge immunity to murine coronaviruses [2], with both studies strongly suggesting that a polyvalent vaccine would be required to protect mice against infection with the many MHV strains that circulate in animal colonies. The current experiments suggest a caveat, however; even a polyvalent vaccine might not eliminate the deleterious effects of MHV on in vitro assays of immune function, since function of cells from mice challenged with homotypic virus was depressed, albeit not to the extent seen after mock vaccination and challenge. Therefore, efficacy testing of any candidate vaccine should include studies to determine whether vaccination 
protects against $T$ cell dysfunction, especially if the targeted vaccinees are to be used in immunologic studies.

The finding of low or negligible MHV-JHM EIA antibody titers in sera of MHV-S-immunized mice (Table 3) was unexpected, since the MHV-JHM EIA has been used to detect MHV-S antibody in sera from mice injected intraperitoneally with infected mouse brain homogenate [35]. The sera from MHV-Simmunized mice did contain MHV antibody based on the IFA test with bivalent antigen. The EIA uses as antigen infected cell monolayers in which about $75 \%$ of the cells are fused [35]. Syncytium formation by MHV relies on the presence of the surface E2 or S glycoprotein which is also the protein against which neutralizing and protective antibodies are directed. Mature virus particles released into the culture medium may also be precipitated when formalin is added to inactivate the virus prior to assay. Thus, this modified enzyme immunoassay may, under certain conditions, be more likely to detect strain-specific antibody than assays that use immobilized soluble antigen. Whether route of inoculation plays a role is currently unknown. However, high MHV-JHM-specific antibody titers were positively correlated in this study with relative, but not complete, protection from MHV-JHM-induced immune dysfunction.

\section{Acknowledgements}

This work was supported by NIH grant RR04507. The authors thank Deborah Winograd, Debby Beck and George Hansen for technical assistance and Dr. Kim Bottomly for providing cytokine-specific monoclonal antibodies and CTLL-2 cells.

\section{References}

1. Barthold SW, Smith AL (1987) Response of genetically susceptible and resistant mice to intranasal inoculation with mouse heptatitis virus JHM. Virus Res 7: 225-239

2. Barthold SW, Smith AL (1989) Virus strain specificity of challenge immunity to coronavirus. Arch Virol 104: 187-196

3. Bia FJ, Thornton GF, Main AJ, Fong CKY, Hsiung GD (1980) Western equine encephalitis mimicking herpes simplex encephalitis. J Am Med Assoc 244: 367-369

4. Boorman GA, Luster MI, Dean JH, Campbell ML, Lauer LA, Talley FA, Wilson RE, Collins MJ (1982) Peritoneal macrophage alterations caused by naturally occurring mouse hepatitis virus. Am J Pathol 106: 110-117

5. Braunsteiner $\mathrm{H}$, Friend $\mathrm{C}$ (1954) Viral hepatitis associated with transplantable mouse leukemia. J Exp Med 100: 665-677

6. Brownstein DG, Barthold SW (1982) Mouse hepatitis virus immunofluorescence in formalin- or Bouin's-fixed tissues using trypsin digestion. Lab Anim Sci 32: 37-39

7. Buckley SM, Casals J (1970) Lassa fever, a new virus disease of man from West Africa. III. Isolation and characterization of the viurs. Am J Trop Med Hyg 19: 680-691

8. Carter JJ, Weinberg AD, Pollard A, Reeves R, Magnuson JA, Magnuson NS (1989) Inhibition of T-lymphocyte mitogenic responses and effects on cell functions by bovine herpesvirus 1. J Virol 63: 1525-1530

9. Casebolt DB, Spalding DM, Schoeb TR, Lindsey JR (1987) Suppression of immune response induction in Peyer's patch lymphoid cells from mice infected with mouse hepatitis virus. Cell Immunol 109: 97-103

10. Cimino GD, Gamper HB, Isaacs ST, Hearst JE (1985) Psoralens as photoactive probes 
of nucleic acid structure and function: organic chemistry, photochemistry, and biochemistry. Annu Rev Biochem 54: 1151-1193

11. Colonna Romano G, Dieli F, Abrignani S, Salerno A, Colizzi V (1986) Inhibition of lymphocyte mitogenesis in mice infected with Newcastle disease virus: viral interference with the interleukin system. Immunology 57: 373-378

12. Dempsey WL, Smith AL, Morahan PS (1986) Effect of inapparent murine hepatitis virus infections on macrophages and host resistance. J Leuk Biol 39: 559-565

13. de Souza MS, Smith AL (1991) Characterization of accessory cell function during acute infection of BALB/cByJ mice with mouse hepatitits virus (MHV), strain JHM. Lab Anim Sci 41: 112-118

14. de Souza MS, Smith AL, Bottomly K (1991) Infection of BALB/cByJ mice with the JHM strain of mouse hepatitis virus alters in vitro splenic $T$ cell proliferation and cytokine production. Lab Anim Sci 41: 99-105

15. Engers HD, Louis JA, Zubler RH, Hirt B (1981) Inhibition of T cell-mediated functions by MVM(i), a parvovirus closely related to minute virus of mice. J Immunol 127: 22802285

16. Gillis S, Ferm MM, Ou W, Smith KA (1978) T cell growth factor: parameters of production and a quantitative microassay for activity. J Immunol 120: 2027-2032

17. Hanson CV (1983) Inactivation of viruses for use as vaccines and immunodiagnostic reagents. In: de la Maza LM, Peterson EM (eds) Medical virology II. Elsevier, New York, pp 45-79

18. Harty JT, Plagemann PG (1988) Formalin inactivation of the lactate dehydrogenaseelevating virus reveals a major neutralizing epitope not recognized during natural infection. J Virol 62: 3210-3216

19. Homberger FR, Smith AL, Barthold SW (1991) Detection of rodent coronaviruses in tissues and cell cultures using polymerase chain reaction. J Clin Microbiol 29: 27892793

20. Hu-Li J, Ohara J, Watson C, Tsang W, Paul WE (1989) Derivation of a T cell line that is highly responsive to IL-4 and IL-2 (CT.4R) and of an IL-2 hyporesponsive mutant of that line (CT.4S). J Immunol 142: 800-807

21. Kraft V, Meyer B (1986) Diagnosis of murine infections in relation to test methods employed. Lab Anim Sci 36: 271-276

22. Lindsey JR (1986) Prevalence of viral and mycoplasmal infections in laboratory rodents. In: Bhatt PN, Jacoby RO, Morse HC, New A (eds) Viral and mycoplasmal infections of laboratory rodents. Effects on biomedical research. Academic Press, New York, pp 801-808

23. LoGrippo GA, Hartman FW (1955) Antigenicity of beta-propiolactone-inactivated virus vaccines. J Immunol 75: 123-128

24. Lucas CJ, Ubels-Postma JC, Rezee A, Galama JMD (1978) Activation of measles virus from silently infected human lymphocytes. J Exp Med 148: 940-952

25. Lussier G, Descoteaux J-P (1986) Prevalence of natural virus infection in laboratory mice and rats used in Canada. Lab Anim Sci 36: 145-148

26. McChesney MB, Altmann A, Oldstone MBA (1988) Suppression of T lymphocyte function by measles virus is due to cell cycle arrest in G1. J Immunol 140: 1269-1273

27. Margolese RG, Israel E, Wainberg MA (1980) Non-specific inhibition by virus particles of human lymphocyte mitogenesis. Clin Exp Immunol 41: 243-251

28. Mosmann TR, Cherwinski H, Bond MW, Giedlin MA, Coffman RL (1986) Two types of murine $\mathrm{T}$ helper cell clones. I. Definition according to profile of lymphokine activities. J Immunol 136: 2348-2357

29. Ohara J, Paul WE (1985) B cell stimulatory factor BSF-1: production of a monoclonal antibody to and molecular characterization of B-cell stimulatory factor-1. Nature 315: 333-336 
30. Small JD, New AE (1981) Prevention and control of mousepox. Lab Anim Sci 31: $616-621$

31. Smith AL (1983) An immunofluorescence test for detection of serum antibody to rodent coronaviruses. Lab Anim Sci 33: 157-160

32. Smith AL, Barthold SW, de Souza MS, Bottomly K (1991) The role of gamma interferon in infection of susceptible mice with murine coronavirus, MHV-JHM. Arch Virol 121: $89-100$

33. Smith AL, Bottomly K, Winograd DF (1987) Altered splenic T cell function of BALB/ $\mathrm{cByJ}$ mice infected with mouse hepatitis virus or Sendai virus. J Immunol 138: 34263430

34. Smith AL, Casals J, Main AJ (1983) Antigenic characterization of Tettnang virus: Complications caused by passage of the virus in mice from a colony enzootically infected with mouse hepatitis virus. Am J Trop Med Hyg 32: 1172-1176

35. Smith AL, Winograd DF (1986) Two enzyme immunoassays for the detection of antibody to rodent coronaviruses. J Virol Methods 14: 335-343

36. Smith AL, Winograd DF, de Souza MS (1991) In vitro splenic T cell responses of diverse mouse genotypes after oronasal exposure to mouse hepatitis virus, strain JHM. Lab Anim Sci 41: 106-111

37. Strayer DS, Skaletsky E, Leibowitz JL (1986) Inhibition of virus replication does not alter malignant rabbit fibroma virus-induced immunosuppression. Clin Exp Immunol 66: $25-36$

38. Suzuki E, Matsubara J, Saito M, Muto T, Nakagawa M, Imaizumi K (1982) Serological survey of laboratory rodents for infection with Sendai virus, mouse hepatitis virus, reovirus type 3 and mouse adenovirus. Jpn J Med Sci Biol 35: 249-254

39. Wainberg MA, Israel E (1980) Viral inhibition of lymhocyte mitogenesis. I. Evidence for nonspecificity of the effect. J Immunol 124: $64-70$

40. Wainberg MA, Portnoy JD, Clecner B, Hubschman S, Lagace-Simard J, Rabinovitch N, Remer Z, Mendelson J (1985) Viral inhibition of lymphocyte proliferative responsiveness in patients suffering from recurrent lesions caused by herpes simplex virus. $\mathrm{J}$ Infect Dis 152: 441-448

41. Watson J, Gillis S, Marbrook J, Mochizuki D, Smith KA (1979) Biochemical and biological characterization of lymphocyte regulatory molecules. I. Purification of a class of murine lymphokines. J Exp Med 150: 849-861

Authors' address: Dr. Abigail L. Smith, Section of Comparative Medicine, Yale University School of Medicine, 333 Cedar Street, P.O. Box 3333, New Haven, CT 06510, U.S.A.

Received October 21, 1991 